\title{
Considering the Cost Analysis of Value Stream in the Lean Improvement
}

\author{
Xiaobing Pei, Zhijie Pei \\ ${ }^{1}$ School of Management, Tianjin University of Technology, Tianjin 300384, China; \\ tjutgongye@126.com
}

Keywords: value stream; value stream mapping (VSM); value stream cost; lean improvement

\begin{abstract}
This paper expand the value stream research and re-recognize the value stream, quality, cost and so on should be considered which can bring value to the whole production when analysis the value stream factors, and also proposed value stream cost analysis process. Finally, combined with the specific case, using the value stream map analysis technique and analysis method of value stream cost to improve the production of basket and makes the balance of production rate increased by $39.5 \%$ and the release of the 753.7 hours every month.
\end{abstract}

\section{Introduction}

At present, to lean improvement of enterprise operation, value stream analysis is widely used as an important tool to manufacturing and other enterprise management. Foreign scholars Don Tapping ${ }^{[1]}$ introduced the implementation of eight steps to value stream mapping in the book "value stream management" which is widely used in every industry. When the enterprise in the use of tools for lean value stream improvement, usually they ignore the analysis of the cost factor; Domestic scholars Yang Qing ${ }^{[2]}$ proposed the lean value concept of the total project life cycle, and pointed out the process of realizing lean project value management and considering the stakeholders which expanded the application of value stream. Pi Sheng $l \mathrm{ei}^{[3]}$ pointed out the quality of the value stream, on the base of the customer establish the basic model diagram quality value stream to management the quality and analysis the factors affecting the quality of the value stream deeply; Wang $\mathrm{Pu}^{[4]}$ cha used the resource value stream and cost accounting method to improve the circulation economy theory of value stream cost accounting and established a new method by combining with other methods which expanded the value stream analysis.

In conclusion, more and more enterprises use value stream for lean improvement, and considered much more factors deeply. The analysis method has turn to the entire value chain and a large number of information flows from the traditional analysis of the whole process of material flow and a small amount of information flow. This article considering of value stream cost factors to lean to the factory to improve on the basis of the value stream map.

\section{Value stream analyses}

\subsection{Expansion Value stream analysis}

Value stream refers to products from raw materials to finished products and give it the value of all activities which including appreciation value activities and non-value added value activities ${ }^{[5]}$. The traditional value stream analysis personnel and material flow from the perspective of the process time by reducing the personnel, material and other non-value added activities to accelerate the process of production flow of value to add value.

With the deepening of the research, the content of the value stream analysis have been made by a separate personnel, material and process, balance time study now extended to the quality of the value stream ${ }^{[3]}$ and the cost of the value stream which can add value to the enterprise. From the point of view of cost, quality, process time and personnel distribution angle analysis of enterprise internal value stream to reducing non-value added factor and product value-added continuously. When analysis stream value cost, due to personnel, sites, equipment, can use time to measure the cost, through analyzing the time utilization, achieve the goal of for cost control. In lean improvement, 
through the analysis of the value stream factors such as cost, quality can quickly identify the influencing factors of quality, cost in the whole value stream, using the flow of product in the process of production value, to achieve the quality of production and cost control.

\subsection{Value stream map analysis}

Value stream map analysis is the effective tool in lean improvement, through the appraisal of each unit on-site, easy to read and mapped the status value stream map symbols and streamline, analysis of enterprise logistics and information flow, lean improvement method is used to analyses the present situation of lean improvement. On this basis to adopt the measures and expected to achieve through the value stream map to reflect in the future. Fundamental purpose is to use the lean value stream map analysis to improve methods of eliminating non-value added activities from the value stream, through analyzing the status quo of value stream map, in the process of lean implementation process of forming a continuous and future target of close to, through the analysis and improve continuously and form a PDCA (Plan - Do - Check - Act) cycle.

\subsection{Value stream cost analysis}

Costs arising from the product (service) each link of the process of life, and in the stream of people, logistics, information flow, cash flow associated with the creation of new values and consumption of resources, the cost of the enterprise are determined by the amount of resources of value, so in the value stream contains more opportunities for cost control [6]. Lean improvement of value stream cost analysis is based on the analysis of the consumption of resources, release more available resources, and resource consumption by humans and machines for production process of processing and service of process, so for humans and machines use case is particular analysis, can release of the available human and material resources. Due to the release of resources to improve the former has already been paid, so the use of these resources for other improvements that can reduce the cost of the enterprise.

\section{The application of value stream analysis in TC enterprises}

\subsection{Present situation of enterprise}

TC plant introduces of lean production mode and we get the present situation of VSM through collecting the dates of big basket product. There are serious unreasonable phenomenon, as shown below.

1. The product model of the plant is predictive push production, the production management department forecasts and formulates production plan according to the market demands and the daily production plan will be distributed to the suppliers and each location, which will lead to the lack of exchange information and feedback between upstream and downstream units and form "information isolated island".

2. Production cycle is not balanced. The time of measurement can reflect oxygen welding process for the bottleneck process, its production cycle is $43 \mathrm{~s}$, restrain the whole production process.

3. According to the production value of big basket stream can obtain that

Value - added ratio $=\frac{\text { added Value time }}{\text { Manuf acturing cycle }+ \text { add Value time }}=\frac{138}{45 \times 3600+138}=0.085 \%$

This means that the factory completed a number of orders for only 0.085 percent can provide customer recognized value, and it doesn't meet customer demand oriented mode of production, the factory's production cycle is $45 \mathrm{~h}$, and the create value time is only 138 seconds.

\subsection{Improvement countermeasures}

1. Promoting the kanban management system and using the pull system control production. We use supermarket to control the production at these units whose continuous flow cannot deliver information to the upstream.

2. Determine the production rhythm of customer demand, customer needs the beat is the single product production target rate for customers to buy sheet product rate, production rhythm and sales beat synchronization

$$
\text { Demand Beat of customer }=\frac{\text { Effective working hours in each shift }}{\text { Custpmer demand in each shift }}=\frac{6.5 \times 3600}{25000 / 22 / 2}=41.2 \mathrm{~s}
$$


The tact time is $41.2 \mathrm{~s}$, and the carbon welded is the bottleneck link in the entire production chain. Through action video analysis, and improve the lighting environment dioxide welding process, 5S rectification daily Making the welding process operating time reduced $17 \mathrm{~s}$.

3. The maximum continuous stream development and continuous process flow will connect, Merging the manufacturing cycle time and downtime is a high efficient production way.

4. Introduction of first-in, first-out pipes, accommodate it as a certain inventory of transportation way.

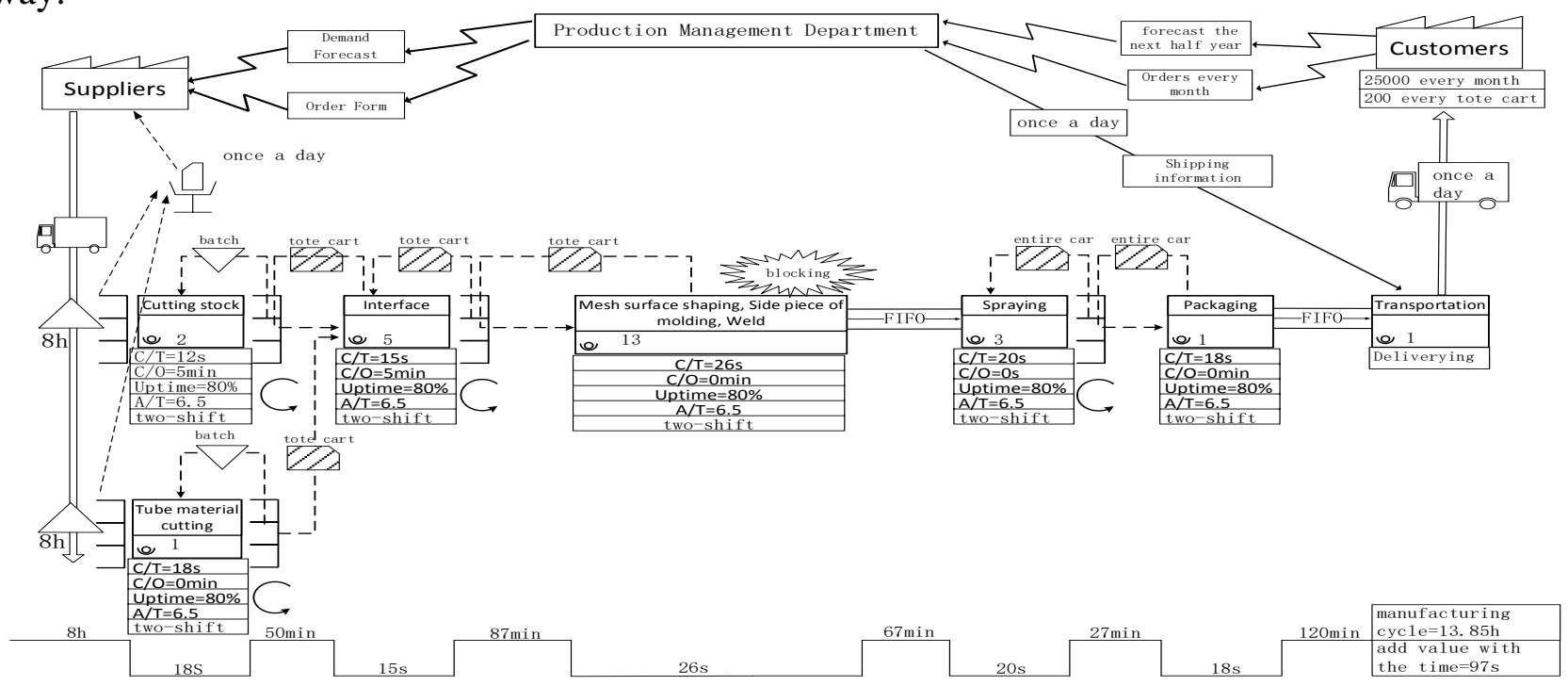

\section{3 value stream cost analysis}

Fig. 1 The improved VSM of TC plant

We use value stream map on the resources ability of man and machine When the resource usage of people are analyzed .The productive time is actual on-demand manufacturing time and cycle time $(\mathrm{C} / \mathrm{T})$, Non-productive time is the sum total of change time $(\mathrm{C} / \mathrm{O})$ and preparation time and administrative work time. Because the machine after the lean improvement without the introduction of advanced equipment, and the original machine don't improvement, so there is no machine preparation of value stream cost analysis table. As can be seen from the table 1, we can summarize the lean improved resource capacity of basked production value.

Table 1 The released resource of improved VSM

\begin{tabular}{|c|c|c|c|c|}
\hline & $\begin{array}{c}\text { Under the current } \\
\text { conditions available } \\
\text { time }\end{array}$ & $\begin{array}{l}\text { Condition available } \\
\text { time in the future }\end{array}$ & $\begin{array}{l}\text { Release } \\
\text { time }\end{array}$ & $\begin{array}{l}\text { Release the } \\
\text { human resources }\end{array}$ \\
\hline Cutting stock & 101. $74 \mathrm{~h}$ & $185.84 \mathrm{~h}$ & $84.1 \mathrm{~h}$ & 0.59 \\
\hline Interface & $39.89 \mathrm{~h}$ & $151.5 \mathrm{~h}$ & $111.6 \mathrm{~h}$ & 0.78 \\
\hline \multirow{3}{*}{$\begin{array}{l}\text { Mesh surface } \\
\text { shaping, Side } \\
\text { piece of } \\
\text { molding, Weld }\end{array}$} & $21.9 \mathrm{~h}$ & \multirow{3}{*}{ 33. $95 \mathrm{~h}$} & \multirow{3}{*}{$138.86 h$} & \multirow{3}{*}{0.97} \\
\hline & 8. $1 \mathrm{~h}$ & & & \\
\hline & $-134.91 \mathrm{~h}$ & & & \\
\hline Packaging & $82.77 \mathrm{~h}$ & $155.5 \mathrm{~h}$ & $72.73 \mathrm{~h}$ & 0.51 \\
\hline customer service & & & $90.67 \mathrm{~h}$ & 0.63 \\
\hline procurement & & & $198.5 \mathrm{~h}$ & 1.39 \\
\hline $\begin{array}{c}\text { finance } \\
\text { department }\end{array}$ & & & $57.2 \mathrm{~h}$ & 0.4 \\
\hline
\end{tabular}

Overall, the total released time is 753.66 hours after lean improved, and have the equivalent of 5.27 resources become available resources. The customer service, purchasing, finance department 
doesn't clearly show in the value stream map and only be measured according to actual situation. Companies can take advantage of the release of these resources for business expansion .In addition, the company can organize the training, to increase organizational flexibility and improve the ability of the reaction of the customer demand diversification.

\section{Plan execution effect}

There were obviously improved after the indicators change. The production units reduce 2 units and the production rhythm is faster than customer demand beats which is $15.2 \mathrm{~s}(41.2 \mathrm{~s}-26 \mathrm{~s})$, can quickly adapt to customer demand, manufacturing cycle is shortened to 13.85 hours. The balance rate of the production flow increased by $39.5 \%$ in the table. The total time is 753.7 hours after lean reform, equivalent to production to reduce the total number of 5 people.

\section{Conclusion}

Value stream map analysis technology is presented in this paper, on the basis of the introduction of value stream cost analysis, and released the available resource, helped lean innovation for the enterprise. Take TC plant as the case study, this paper offers reference for other lean improvement mainly has the following points: (1) The cost of value stream should be considered when analyses value stream cost to release more resources. (2)The cost of value stream analysis should not only consider the production unit of value stream map, also consider other service for the production of the unit.

\section{References}

[1]. Tapping D. Value Stream Management: Eight Steps to Planning, Mapping and Sustaining Lean Improvement [M].Productivity Press, 2002: 10-15.

[2]. Yang qing, Qiu yuanhua, Zhang jing. Lean project value management and value stream analysis method research [J]. Scientific research 2006, 4 (2) : 249-255.

[3]. Pi shenglei. Quality value stream and application [J]. Journal of technology economy, 2013:122-130.

[4]. Wang pucha, Chen yan hua, liu duo. the resource value stream cost accounting methods applied research under Circular economy [J]. Science and technology management research, 2013, 17:232-235.

[5]. Jing quanzhong, Yang jing. Based on the value stream map of sucker rod production line balancing optimization study [J]. Industrial engineering and management, 2014, 19 (5) : 18-23.

[6]. Chi xiaoying. Gu juan. Value chain analysis method to control the cost of enlightenment [J]. Journal of accounting, Shanghai 2000. 8:46 - 47. 